\title{
Traditional $v$. modern dietary patterns among a population in western Austria: associations with body composition and nutrient profile
}

\author{
Sabrina Egg ${ }^{1, *}$, Judith Erler ${ }^{1}$, Bernhard Perktold ${ }^{1}$, Verena Hasenegger $^{2}$, Petra Rust $^{2}$, \\ Reinhold Ramoner ${ }^{1}$, Jürgen König ${ }^{2}$ and Anna Elisabeth Purtscher ${ }^{1}$ \\ 'Department of Dietetics, Health University of Applied Sciences Tyrol, Innrain 98, 6020 Innsbruck, Austria: \\ ${ }^{2}$ Department of Nutritional Sciences, University of Vienna, Vienna, Austria
}

Submitted 6 February 2018: Final revision received 21 September 2018: Accepted 22 October 2018: First published online 29 November 2018

\begin{abstract}
Objective: The present study aimed to identify dietary patterns, compare dietary patterns regarding nutrient profile and investigate the association between dietary patterns and body composition in a population in western Austria.

Design: In a cross-sectional study, eating habits, anthropometric measurements and body composition were assessed. Food intake was collected by two nonconsecutive $24 \mathrm{~h}$ recalls. Factor analysis (principal component analysis) with complementary cluster analysis was applied to identify dietary patterns. Associations of dietary patterns with body composition and nutrient profile were examined by the $t$ test, one-way ANOVA and ANCOVA with Bonferroni's correction. The $\chi^{2}$ test was used for categorical variables.

Setting: Tyrol, western Austria, 2014-2015.

Participants: Adults ( $n$ 463) aged 18-64 years.

Results: Three dietary patterns were derived, labelled as the 'health-conscious', the 'western' and the 'traditional' dietary pattern. After adjustment for confounding variables, individuals following the traditional and western patterns were more likely to be overweight/obese $(P<0.001)$ and to have a higher body fat percentage $(P<0 \cdot 05)$. Individuals following the traditional dietary pattern consumed significantly more SFA and less PUFA and dietary fibre $(P<0 \cdot 001)$ than those in the other groups.

Conclusions: Individuals who mostly eat in a traditional way should be encouraged to increase their consumption of vegetables, fruits, whole grains and healthy fats. It is important to know local eating habits not only for planning individual nutritional therapy, but also for well-directed public health actions.
\end{abstract}

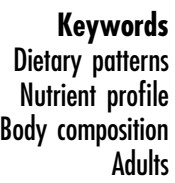

Current nutrition recommendations worldwide emphasize dietary patterns that offer nutrient-dense foods and low intake of energy-dense foodstuffs, in order to lower the risk of overweight and obesity as well as other noncommunicable diseases $(\mathrm{NCD})^{(1-3)}$. Despite those recommendations and health-care campaigns, the prevalence of nutrition-related NCD is rising worldwide $^{(4)}$, Austria included $^{(5)}$. According to estimates in Austria, annual costs of $€ 227 \cdot 7-1138.5$ million arise every year as part of public health expenditures ${ }^{(6)}$.

As in all Western countries, in Austria too eating behaviour has changed over the past decades. While during and after the world wars cheap foods such as potatoes and legumes were consumed regularly to ensure sufficient food intake, a shift towards meat and meat products took place afterwards and their intake almost doubled from 1948 to 1982 , while also fat intake increased from 32 to $42 \%$ of total energy intake (E \%) during the same period ${ }^{(7)}$. An east-west gap had already been apparent early in these years and is still present nowadays. Food intake, and thus nutrient profile as well as body composition, are affected by this gap, as shown in the Austrian Nutrition Study $2012^{(8)}$ : BMI, waist circumference and body fat percentage (BFP) in adults were significantly higher in eastern Austria than in western Austria. Also, energy intake in women was significantly higher in the east (8000 kJ (1912 kcal)) than in the west $(7301 \mathrm{~kJ}(1745 \mathrm{kcal}))$ and differences in fat intake (higher in the east) were apparent.

There has been substantial effort to assess the influence of nutrients on certain health outcomes ${ }^{(9,10)}$. However, 
due to the complexity of diet and lifestyle factors, the results regarding a correlation between one single nutrient and specific outcomes are inconsistent. Thus, during the past years, instead of researching isolated compounds, identifying and analysing dietary patterns has been an indispensable approach within nutritional epidemiology ${ }^{(11,12)}$. Similarly, nutritional recommendations and guidelines worldwide have long emphasized single nutrients rather than diet overall, resulting in difficulties for individuals to apply nutrient-focused recommendations in everyday life. Modern nutritional science now provides substantial evidence for how foods and food-based patterns affect health, resulting in more effective approaches for the prevention of NCD. Eventually, Mozzaffarian and Ludwig $^{(13)}$ describe the need for the replacement of nutrient-based targets by food-based targets, as national and international organizations update their dietary guidelines.

To identify dietary patterns, they are commonly derived from the amounts, frequency and variety of foods that are consumed in a specific population of interest. As mentioned above, previous studies have already shown that dietary patterns play a crucial role in the development of NCD, such as obesity, type 2 diabetes mellitus, hypertension, CVD and metabolic syndrome ${ }^{(14-22)}$. In this context, also body composition represents a risk factor and is dependent on dietary patterns as well as on physical activity. With commonly measured variables for body composition, it is possible to draw conclusions about the health status. Those variables often include BFP, body cell mass or muscle mass (BCM) as well as phase angle (PA) and extracellular water (ECW) which can be indicators of malnutrition $^{(23)}$. Measurement of body composition provides conclusive parameters and, together with sufficient nutrient intake, they have a strong impact on the development and progress of $\mathrm{NCD}^{(24-27)}$.

Finally, it is important to recognize the differences in dietary patterns and nutrient profiles within a certain population in order to understand possible associations with regional occurrence of diseases. In most countries, tradition plays an important role when it comes to food preferences ${ }^{(28,29)}$. Some of Austria's traditional foods and dishes - such as typical milk products (e.g. Tyrolean cheese), meat and meat products (e.g. Tyrolean Speck), dumplings and sweet dishes (e.g. Kaiserschmarrn, Germknödel), as well as soups and stews - are protected and registered in the Database Of Origin and Registration by the European Commission ${ }^{(30)}$. They are rooted in Austria's food culture and, therefore, have an impact on nutrient intakes.

In Austria, the identification and analysis of dietary patterns in a population to that extent have not been carried out yet and consequently represents an appropriate approach for our study. Therefore, our aim was to identify dietary patterns, characterize their nutrient profiles and investigate their association with parameters of body composition in adults living in the tradition-rich alpine area of Austria, Tyrol.

\section{Study design and methods}

\section{Study population}

In the current cross-sectional study, body composition and eating habits of 463 adults (aged 18-64 years) in Tyrol in Austria were assessed between October 2014 and October 2015 by the Department of Dietetics at the Health University of Applied Sciences Tyrol. The responsible ethics committee RCSEQ (The Research Committee for Scientific and Ethical Questions), an authorized committee at the UMIT (Private University for Health Sciences, Medical Informatics and Technology), reviewed and approved the study protocol (reference number 728/13).

The European Parliament and the Council of the European Union have, by Regulation No. 1059/2003, created a common statistical classification of territorial units in order to 'enable the collection, compilation and dissemination of harmonized regional statistics in the Community $^{\text {(31) }}$. For this system of territorial units for statistics, the acronym NUTS (Nomenclature of Territorial Units for Statistics) is used ${ }^{(32)}$. Because of budgetary reasons the statistical population was limited to the NUTS-3 region which includes urban and rural areas of Innsbruck. The data provided by Statistics Austria ${ }^{(33)}$ are based upon the register of residents and were stratified by sex and age by dividing the population into the age groups of 18-24, 25-50 and 51-64 years as proposed by the European Commission $^{(34)}$. In order to obtain representative results for this region, a minimum net sample of 400 individuals was required with a significance level of $\pm 5 \%(P<0.05)$, within a confidence interval of $95 \%$ for a population of 193386 individuals in the year of 2014. The calculation and the drawing of the random sample and the corresponding household addresses, including contact persons and telephone numbers, were conducted by an opinion research institute in Vienna (SDI-Research, Dr Villani \& Partner KG; http://www.sdi-research.at/). The random sample included 1376 individuals who were provided with a unique identification number. Exclusion criteria were based on age and permanent place of residence as well as extreme energy intake (either too low or too high), which was determined by the Goldberg cut-off points ${ }^{(35,36)}$. After receiving a written invitation, all individuals were contacted via telephone. Due to non-response, the eventual number of participants was 358 and thus lower than the required minimum net sample of 400 . Also, we observed a higher response rate in women (32\%) than in men (20\%). These circumstances made additional recruitment of participants, especially young men, necessary and took place in regional companies, nevertheless ensuring representativity by maintaining the population's structure. Two participants were excluded by the Goldberg cut-off points and eighteen 
dropped out of the study. Eventually, a total of 463 participants (228 men and 235 women) completed the study. A flowchart of the recruitment process can be found in the online supplementary material, Supplemental Fig. 1.

\section{Assessment of dietary intake}

In the course of one year, and thus with consideration of seasonal differences, the survey was conducted on the basis of two non-consecutive $24 \mathrm{~h}$ recalls, the first of which was carried out as a computer-assisted personal interview and the second as a computer-assisted telephone interview six weeks later. To obtain the most accurate information on food consumption, the computer software Globodiet $^{\circledR(37)}$ (formerly EPICSoft), which was developed by the International Agency for Research on Cancer and further adapted for Austria by researchers at the Department of Nutritional Sciences in Vienna, was used with the corresponding photo book. The participants were asked in detail about the type and quantity of foods consumed in a past $24 \mathrm{~h}$ period. Reconstruction of food consumption was standardized in several phases in order to enhance precision of memory recollection.

The nutritional assessment was planned and carried out in accordance with the best practice guidelines of the European Food Safety Authority ${ }^{(38)}$ and the German National Consumption Study (NVSII) ${ }^{(39)}$. Standardized conditions were applied for data collection throughout the whole study. The reported foods collected during the interviews were linked to the German food composition database Bundeslebensmittelschlüssel (BLS) version 3.02 ${ }^{(40)}$.

\section{Derivation of dietary patterns}

Food items assessed by the $24 \mathrm{~h}$ recalls were categorized into forty food groups. Those food groups were defined by the similarity of food items regarding their nutrient profile (e.g. carbohydrates, dietary fibre, fats, protein) and their affiliation to common main food groups (e.g. milk and milk products, grains, vegetables) based on the classification of the BLS. Concurrently, the mass (in grams) of food items consumed was combined within the appropriate food groups for the following derivation of dietary patterns.

Factor analysis of principal components (PCA) and cluster analysis (CA) are common multivariate statistical procedures to empirically derive dietary patterns. PCA reduces food intake data into patterns based upon intercorrelations between dietary items or food groups, whereas CA reduces data into patterns based on individual differences in mean intakes ${ }^{(11)}$. For $\mathrm{CA}$, uncorrelated items are useful but rare when it comes to dietary intake ${ }^{(41)}$. Therefore, PCA prior to CA with the uncorrelated factor scores as input variables is reasonable and had also been carried out in previous studies ${ }^{(42-44)}$. With this approach, the structure of the data can be investigated and subsequently simplified. Although this approach is comprehensible, it has its limitations which are addressed below ('Discussion' section).

After measuring the sampling adequacy by the KaiserMeyer-Olkin test with a value of 0.57 and Bartlett's test of sphericity $(P<0 \cdot 001)$, PCA was applied to derive patterns from the food groups and determine factor loadings for each group. To maintain uncorrelated factors and enhance data interpretability obtained factors were rotated orthogonally via Varimax rotation. Break in the scree plot, eigenvalues $>1$ and interpretability were used to evaluate factors and to determine which factors were relevant for further analysis. Absolute factor loadings above 0.20 were considered to contribute significantly to the pattern. Consequently, a three-factor solution was found with factor 1 explaining $7.7 \%$ of the variance, factor 2 explaining $5.3 \%$ and factor 3 explaining $4.2 \%$. Together, they explained $17.2 \%$ of the total variance.

To further classify the study population by their dietary patterns, a complementary CA was conducted with the factor loadings calculated by the PCA. Participants were grouped into clusters based on the Euclidean distances between observations using the $k$-mean method. This guaranteed that distances between observations in the same cluster are less than all distances between observations in different clusters. Reflecting the dietary patterns, the solution of three clusters was examined and approved.

\section{Assessment of anthropometric and other variables}

Body composition was determined by standardized measurements of body height, weight, waist and hip circumference. Additionally, BCM, BFP, PA and ECW were determined by bioelectrical impedance analysis. BMI was calculated by dividing the weight (in kilograms) by the square of height (in metres), and BMI values of 25.00$29.99 \mathrm{~kg} / \mathrm{m}^{2}$ and $\geq 30.00 \mathrm{~kg} / \mathrm{m}^{2}$ were considered as overweight and obese, respectively ${ }^{(45)}$.

\section{Statistical analysis}

A descriptive analysis of the main characteristics of interest was performed. The $t$ test was applied for sex, age, BFP, $\mathrm{BCM}, \mathrm{PA}$ and ECW. One-way ANOVA as well as ANCOVA adjusted for sex, age and total energy intake with Bonferroni's correction were applied to compare means across the clusters of dietary patterns. The $\chi^{2}$ test was used for categorical variables. All $P$ values presented are two-tailed; $P<0.05$ was considered significant. All analyses were performed using the statistical software package IBM SPSS Statistics version $24^{\circledR}$.

\section{Results}

\section{Characteristics of the participants}

A total of 463 participants ( 235 women and 228 men) aged between 18 and 64 years were included in the analysis. 
Mean age was 40.4 years and mean BMI was $24.5 \mathrm{~kg} / \mathrm{m}^{2}$. Women's mean BMI $\left(23.6 \mathrm{~kg} / \mathrm{m}^{2}\right)$ was lower than men's $\left(25.4 \mathrm{~kg} / \mathrm{m}^{2}\right)$. Of the women, $28.9 \%$ were overweight or obese (BMI $\geq 25.00 \mathrm{~kg} / \mathrm{m}^{2}$ ) compared with $45.6 \%$ of the men. Further characteristics are listed in Table 1.

\section{Dietary patterns}

Three factors were extracted through PCA using forty food groups, as shown in Table 2. Using CA based on the factor loadings (see Table 3) three major dietary patterns were defined: the 'health-conscious' dietary pattern, the 'traditional' dietary pattern and the 'western' dietary pattern. The health-conscious dietary pattern was characterized by high intakes of vegetables, fruits, whole grains, low-fat milk products and cheese, vegetable oils, nuts and seeds, poultry, soya and other plant-based products as well as protein shakes/meal substitutes, and low intakes of highsugar beverages, refined bread, butter, processed meat, desserts and cakes, and alcoholic beverages. The traditional dietary pattern had high factor loadings on coffee and green/black tea, potatoes, high-fat milk products, eggs, margarine, pork, sweets and sugars, desserts and cakes as well as soups and stews, but low factor loadings on legumes, refined grains, vegetable oils, and soya and other plant-based products. In the western dietary pattern, mainly pure fruit and vegetable juices, high-sugar beverages, refined grains, beef, pork, poultry, other meat and processed meat as well as fast food, sauces and protein shakes/meal substitutes were consumed. Herbal teas, legumes and fruits were negatively associated with this pattern. About $25 \%$ of the study population could be allocated to the health-conscious ( $n$ 118), $10 \cdot 8 \%$ to the western ( $n 50)$ and $63.7 \%$ to the traditional dietary pattern ( $n$ 295).

Investigated demographic and behavioural characteristics, body composition and nutrient profile of the study population across the clusters of dietary patterns are shown in Table 4. For better comparability, the variables BMI, overweight/obese, BFP, BCM, PA, ECW and total energy intake were adjusted for sex and age. All variables describing the dietary intake were additionally adjusted by total energy intake. As for the characteristics of the study population, individuals following the western dietary pattern were mainly male, tended to be younger and to smoke more, whereas individuals following the healthconscious dietary pattern were mainly young females who took nutritional supplements and smoked less. Those in the group of the traditional dietary pattern were the oldest, with equal proportions of women and men.

\section{Dietary patterns and body composition}

Dietary patterns and variables of body composition are shown in Table 4. BMI and prevalence of overweight/ obesity were highest in individuals who followed the

Table 1 Characteristics of the study population of adults aged 18-64 years ( $n$ 463), Tyrol, western Austria, 2014-2015

\begin{tabular}{|c|c|c|c|c|c|c|}
\hline & \multicolumn{2}{|c|}{$\begin{array}{l}\text { Women } \\
(n 235)\end{array}$} & \multicolumn{2}{|c|}{$\begin{array}{c}\text { Men } \\
(n 228)\end{array}$} & \multicolumn{2}{|c|}{$\begin{array}{c}\text { Total } \\
(n 463)\end{array}$} \\
\hline & Mean & SD & Mean & SD & Mean & SD \\
\hline Age (years) & $41 \cdot 0$ & 12.9 & $39 \cdot 9$ & $12 \cdot 9$ & $40 \cdot 4$ & $12 \cdot 9$ \\
\hline Height (cm) & $166 \cdot 7$ & 5.9 & $178 \cdot 9$ & $7 \cdot 2$ & $172 \cdot 7$ & 8.9 \\
\hline Weight $(\mathrm{kg})$ & 65.5 & $13 \cdot 4$ & $81 \cdot 4$ & $14 \cdot 6$ & $73 \cdot 3$ & $16 \cdot 1$ \\
\hline Waist circumference (cm) & 85.9 & 11.71 & 91.39 & $11 \cdot 8$ & 88.6 & 12.9 \\
\hline Hip circumference $(\mathrm{cm})$ & $100 \cdot 2$ & $10 \cdot 1$ & $100 \cdot 9$ & $7 \cdot 4$ & $100 \cdot 5$ & $8 \cdot 9$ \\
\hline Waist-to-hip ratio & 0.86 & 0.06 & 0.90 & 0.07 & 0.88 & 0.07 \\
\hline BMI $\left(\mathrm{kg} / \mathrm{m}^{2}\right)$ & $23 \cdot 6$ & 4.9 & $25 \cdot 4$ & $4 \cdot 0$ & 24.5 & 4.5 \\
\hline BFP (\%) & 28.4 & $7 \cdot 7$ & $18 \cdot 8$ & $7 \cdot 2$ & 23.7 & $8 \cdot 9$ \\
\hline BCM (\%) & $36 \cdot 6$ & 4.5 & $45 \cdot 9$ & $5 \cdot 3$ & $41 \cdot 2$ & $6 \cdot 8$ \\
\hline ECW (\%) & $45 \cdot 6$ & 2.6 & $40 \cdot 6$ & $2 \cdot 8$ & $43 \cdot 1$ & 3.7 \\
\hline $\mathrm{PA}\left({ }^{\circ}\right)$ & $6 \cdot 1$ & 0.6 & $7 \cdot 3$ & 0.7 & 6.7 & 0.9 \\
\hline Overweight/obese (\%) & \multicolumn{2}{|c|}{28.9} & \multicolumn{2}{|c|}{$45 \cdot 6$} & \multicolumn{2}{|c|}{$37 \cdot 3$} \\
\hline Dietary supplements (\%) & \multicolumn{2}{|c|}{$40 \cdot 4$} & \multicolumn{2}{|c|}{$29 \cdot 4$} & \multicolumn{2}{|c|}{34.9} \\
\hline Smoking (\%) & \multicolumn{2}{|c|}{$21 \cdot 7$} & \multicolumn{2}{|c|}{$26 \cdot 8$} & \multicolumn{2}{|c|}{$24 \cdot 3$} \\
\hline Vegetarian (\%) & \multicolumn{2}{|c|}{3.4} & \multicolumn{2}{|c|}{$2 \cdot 2$} & \multicolumn{2}{|c|}{$2 \cdot 8$} \\
\hline Vegan (\%) & \multicolumn{2}{|c|}{2.6} & \multicolumn{2}{|c|}{0.9} & \multicolumn{2}{|c|}{$1 \cdot 7$} \\
\hline Migration background (\%) & \multicolumn{2}{|c|}{$23 \cdot 8$} & \multicolumn{2}{|c|}{$23 \cdot 2$} & \multicolumn{2}{|c|}{$23 \cdot 5$} \\
\hline \multicolumn{7}{|l|}{ Education (\%) } \\
\hline Elementary school & \multicolumn{2}{|c|}{0.4} & \multicolumn{2}{|c|}{0.0} & \multicolumn{2}{|c|}{0.2} \\
\hline Secondary school & \multicolumn{2}{|c|}{0.9} & \multicolumn{2}{|c|}{0.9} & \multicolumn{2}{|c|}{0.9} \\
\hline Apprenticeship & \multicolumn{2}{|c|}{$14 \cdot 6$} & \multicolumn{2}{|c|}{$26 \cdot 6$} & \multicolumn{2}{|c|}{$20 \cdot 4$} \\
\hline Professional school & & & & & & \\
\hline School with higher education (matura) & & & & & & \\
\hline University & & & & & & \\
\hline Other & & & & & & \\
\hline Occupation (\%) & & & & & & \\
\hline Full-time & & & & & & \\
\hline Part-time & & & & & & \\
\hline
\end{tabular}

BFP, body fat percentage; BCM, body cell mass or muscle mass; ECW, extracellular water; PA, phase angle. 
Table 2 Factor loadings of three major factor solutions after applying principal component analysis to food items consumed by the study population of adults aged 18-64 years ( $n$ 463), Tyrol, western Austria, 2014-2015

\begin{tabular}{|c|c|c|c|}
\hline Food group & Factor 1 & Factor 2 & Factor 3 \\
\hline Water and mineral water & 0.467 & 0.347 & - \\
\hline Fruit and vegetable juices & - & 0.296 & - \\
\hline High-sugar beverages & -0.293 & 0.425 & - \\
\hline Sugar-reduced beverages & - & - & - \\
\hline Coffee and green or black tea & - & - & 0.522 \\
\hline Herbal teas & - & -0.475 & - \\
\hline Vegetables & 0.452 & - & - \\
\hline Legumes & - & -0.228 & -0.359 \\
\hline Fruits & 0.522 & -0.284 & - \\
\hline Refined bread & -0.452 & - & - \\
\hline Wholegrain bread & 0.285 & - & - \\
\hline Refined grains & - & 0.347 & -0.317 \\
\hline Whole grains and others & 0.478 & - & - \\
\hline Potatoes & - & - & 0.313 \\
\hline Milk and milk products, high-fat & - & - & 0.235 \\
\hline Milk and milk products, low-fat & 0.414 & - & - \\
\hline Cheese, $>35 \%$ fat in dry matter & - & - & - \\
\hline Cheese, $<35 \%$ fat in dry matter & 0.494 & - & - \\
\hline Butter & -0.407 & - & - \\
\hline Vegetable oils & 0.288 & - & -0.425 \\
\hline Nuts and seeds & 0.423 & - & - \\
\hline Margarine & - & - & 0.261 \\
\hline Eggs & - & - & 0.209 \\
\hline Beef & - & 0.314 & - \\
\hline Pork & - & 0.253 & 0.300 \\
\hline Poultry & 0.292 & 0.545 & - \\
\hline Other meat & - & 0.263 & - \\
\hline Processed meat & -0.367 & 0.337 & - \\
\hline Fish and seafood & - & - & - \\
\hline Sweets and sugars & - & - & 0.220 \\
\hline Desserts and cakes & -0.239 & - & 0.284 \\
\hline Snacks & - & - & - \\
\hline Fast food & - & 0.340 & - \\
\hline Alcoholic beverages & -0.272 & - & - \\
\hline Sauces & - & 0.338 & - \\
\hline Alternative sweeteners & - & - & - \\
\hline Soups and stews & - & - & 0.422 \\
\hline Protein shakes/meal substitutes & 0.290 & 0.297 & - \\
\hline Soya and other plant-based products & 0.307 & - & -0.234 \\
\hline Dietary supplements & 0.336 & - & - \\
\hline
\end{tabular}

Factor loadings are identical to Pearson's correlation coefficients. Factor loadings with absolute values $<0.20$ are not shown for simplicity.

Table 3 Classification of participants by cluster analysis in the study population of adults aged 18-64 years (n 463), Tyrol, western Austria, 2014-2015

\begin{tabular}{|c|c|c|c|c|c|c|}
\hline & \multicolumn{2}{|c|}{ Health-conscious dietary pattern } & \multicolumn{2}{|c|}{ Traditional dietary pattern } & \multicolumn{2}{|c|}{ Western dietary pattern } \\
\hline & Mean & SD & Mean & SD & Mean & SD \\
\hline Factor $1^{*}$ & $0.94^{a}$ & 0.81 & $-0.47^{b}$ & 0.56 & $0.54^{c}$ & 1.49 \\
\hline Factor 2 & $-0.62^{a}$ & 0.71 & $-0.09^{b}$ & 0.61 & $2 \cdot 01^{c}$ & 0.94 \\
\hline Factor 3 & $-0.38^{a}$ & 1.01 & $\mathbf{0} \cdot 18^{\mathrm{b}}$ & 0.85 & $-0 \cdot 13^{a}$ & 1.32 \\
\hline
\end{tabular}

western dietary pattern. Also, BFP was the highest in women while BCM was the lowest. Although most body composition values of individuals following the traditional dietary pattern were just below those of the western dietary pattern, BFP and BCM of men were higher and lower, respectively. Individuals following the healthconscious dietary pattern had the lowest BMI and the lowest prevalence of overweight/obesity.

\section{Dietary patterns and nutrient profile}

As seen in Table 4, individuals following the western dietary pattern had higher energy and protein intakes, a lower intake of carbohydrates as well as higher consumption of cholesterol, $\mathrm{Zn}$ and uric acid compared with individuals in both other patterns. Individuals who followed the health-conscious dietary pattern consumed less energy and had higher intakes of carbohydrates, dietary 
Table 4 Participant characteristics according to dietary pattern among the study population of adults aged 18-64 years ( $n$ 463), Tyrol, western Austria, 2014-2015

\begin{tabular}{|c|c|c|c|c|c|c|c|}
\hline & \multicolumn{2}{|c|}{$\begin{array}{l}\text { Health-conscious dietary pattern } \\
\text { ( }(\text { 118) }\end{array}$} & \multicolumn{2}{|c|}{$\begin{array}{l}\text { Traditional dietary pattern } \\
\qquad(n \text { 295) }\end{array}$} & \multicolumn{2}{|c|}{$\begin{array}{l}\text { Western dietary pattern } \\
\qquad(n 50)\end{array}$} & \multirow[b]{2}{*}{$P$ value } \\
\hline & Mean & SE & Mean & SE & Mean & SE & \\
\hline Gender, women (\%) & \multicolumn{2}{|c|}{$72 \cdot 9$} & \multicolumn{2}{|c|}{$48 \cdot 8$} & \multicolumn{2}{|c|}{$10 \cdot 0$} & $<0.001$ \\
\hline Age (years) & 39.8 & 1.1 & 42.5 & 0.7 & 29.9 & 1.8 & $<0.001$ \\
\hline BMI $\left(\mathrm{kg} / \mathrm{m}^{2}\right)^{*}$ & $24 \cdot 0$ & 0.4 & 24.4 & 0.3 & $26 \cdot 4$ & 0.6 & 0.003 \\
\hline BFP, women (\%)* & 28.9 & $0 \cdot 8$ & $27 \cdot 9$ & 0.6 & $33 \cdot 1$ & $3 \cdot 2$ & 0.204 \\
\hline BFP, men $(\%)^{*}$ & $16 \cdot 0$ & 1.2 & 19.5 & 0.6 & $18 \cdot 3$ & $1 \cdot 1$ & 0.029 \\
\hline BCM, women (\%)* & $36 \cdot 2$ & 0.5 & $37 \cdot 0$ & 0.4 & $35 \cdot 2$ & 1.9 & 0.316 \\
\hline $\mathrm{BCM}$, men $(\%)^{\star}$ & $47 \cdot 0$ & 0.9 & $45 \cdot 4$ & 0.4 & $47 \cdot 0$ & 0.8 & 0.085 \\
\hline ECW, women $(\%)^{*}$ & $45 \cdot 8$ & 0.3 & $45 \cdot 5$ & 0.2 & $44 \cdot 1$ & 1.2 & 0.321 \\
\hline $\mathrm{ECW}$, men $(\%)^{\star}$ & $41 \cdot 1$ & 0.4 & $40 \cdot 7$ & 0.2 & 39.7 & 0.4 & 0.048 \\
\hline PA, women $\left({ }^{\circ}\right)^{\star}$ & $6 \cdot 0$ & 0.1 & $6 \cdot 1$ & 0.1 & $6 \cdot 4$ & 0.3 & 0.323 \\
\hline $\mathrm{PA}$, men $\left({ }^{\circ}\right)^{*}$ & $7 \cdot 2$ & 0.1 & $7 \cdot 3$ & 0.1 & 7.5 & 0.1 & 0.044 \\
\hline Overweight/obese (\%) & \multicolumn{2}{|c|}{$26 \cdot 3$} & \multicolumn{2}{|c|}{40.0} & \multicolumn{2}{|c|}{46.0} & 0.013 \\
\hline Dietary supplement intake (\%) & \multirow{2}{*}{\multicolumn{2}{|c|}{$\begin{array}{l}54 \cdot 2 \\
13 \cdot 6\end{array}$}} & \multicolumn{2}{|c|}{$27 \cdot 8$} & \multicolumn{2}{|c|}{32.0} & $<0.001$ \\
\hline Smoking (\%) & & & & & 40 & & 0.001 \\
\hline \multicolumn{8}{|l|}{ Dietary intake† } \\
\hline Energy (kJ)‡ & 7955.9 & $258 \cdot 2$ & $9044 \cdot 6$ & $146 \cdot 4$ & $10230 \cdot 7$ & $590 \cdot 8$ & $<0.001$ \\
\hline Energy (kcal)‡ & 1901.5 & 61.7 & 2161.7 & $35 \cdot 0$ & $2445 \cdot 2$ & 141.2 & $<0.001$ \\
\hline Carbohydrates (E\%) & $48 \cdot 7$ & 0.9 & 47.5 & 0.5 & $42 \cdot 8$ & $2 \cdot 1$ & 0.032 \\
\hline Protein (E\%) & $15 \cdot 5$ & 0.4 & $14 \cdot 3$ & 0.2 & 21.4 & 1.0 & $<0.001$ \\
\hline Fat $(\mathrm{E} \%)$ & 35.5 & 0.9 & 36.5 & $0 . \overline{5}$ & 33.9 & 1.9 & 0.249 \\
\hline Fibre $(g)$ & 31.5 & 0.9 & $17 \cdot 9$ & 0.5 & $18 \cdot 2$ & $2 \cdot 1$ & $<0.001$ \\
\hline SFA (g) & 33.9 & 1.0 & 39.6 & 0.6 & 32.4 & $2 \cdot 3$ & $<0.001$ \\
\hline MUFA (g) & 28.9 & 0.9 & 28.9 & 0.5 & 28.2 & 1.9 & 0.936 \\
\hline PUFA $(g)$ & $15 \cdot 2$ & 0.6 & $10 \cdot 2$ & 0.3 & 11.1 & 1.4 & $<0.001$ \\
\hline$n-3$ Fatty acids $(\mathrm{g})$ & 2.9 & 0.2 & 1.5 & 0.1 & 1.7 & 0.6 & $<0.001$ \\
\hline$n-6$ Fatty acids $(\mathrm{g})$ & $12 \cdot 3$ & 0.5 & 8.7 & 0.3 & 9.4 & $1 \cdot 1$ & $<0.001$ \\
\hline$n-6: n-3$ & \multicolumn{2}{|c|}{$4: 1$} & \multicolumn{2}{|c|}{$6: 1$} & \multicolumn{2}{|c|}{$6: 1$} & $<0.001$ \\
\hline Cholesterol (mg) & 241.5 & 14.8 & 301.0 & 8.3 & $374 \cdot 3$ & 33.4 & $<0.001$ \\
\hline Uric acid (mg) & 444.4 & 14.0 & 371.3 & 7.8 & 571.4 & 31.7 & $<0.001$ \\
\hline Vitamin A (mg) & 1.7 & 0.1 & 1.2 & 0.1 & 1.4 & 0.3 & 0.001 \\
\hline$\beta$-Carotene $(\mathrm{mg})$ & $6 \cdot 2$ & 0.4 & $3 \cdot 1$ & 0.2 & 4.9 & 0.9 & $<0.001$ \\
\hline Vitamin D ( $\mu \mathrm{g})$ & $2 \cdot \overline{7}$ & 0.3 & $2 \cdot 2$ & 0.1 & $2 \cdot 4$ & 0.6 & 0.177 \\
\hline Vitamin E (mg) & 14.4 & 0.5 & $10 \cdot 0$ & 0.3 & 11.7 & 1.2 & $<0.001$ \\
\hline Folate $(\mu \mathrm{g})$ & $332 \cdot 8$ & $10 \cdot 9$ & 220.5 & $6 \cdot 1$ & $272 \cdot 2$ & 24.7 & $<0.001$ \\
\hline Vitamin C (mg) & $148 \cdot 7$ & 7.8 & $102 \cdot 1$ & 4.3 & 148.6 & $17 \cdot 6$ & $<0.001$ \\
\hline Vitamin $B_{12}(\mu \mathrm{g})$ & 4.5 & 0.3 & 4.7 & 0.2 & $7 \cdot 1$ & 0.6 & 0.001 \\
\hline $\mathrm{Ca}(\mathrm{mg})$ & $1022 \cdot 3$ & 34.9 & 964.4 & $19 . \overline{5}$ & 989.2 & 78.9 & 0.350 \\
\hline $\mathrm{K}(\mathrm{mg})$ & $3542 \cdot 7$ & 88.6 & 2671.2 & $49 \cdot 4$ & 2972.5 & $200 \cdot 4$ & $<0.001$ \\
\hline $\mathrm{Mg}(\mathrm{mg})$ & 438.8 & $10 \cdot 4$ & 319.8 & 5.7 & $358 \cdot 3$ & 23.4 & $<0.001$ \\
\hline $\mathrm{Fe}(\mathrm{mg})$ & $14 \cdot 7$ & 0.4 & 11.7 & 0.2 & 13.4 & 0.8 & $<0.001$ \\
\hline $\mathrm{Zn}(\mathrm{mg})$ & 11.2 & 0.3 & $10 \cdot 3$ & 0.2 & 13.6 & 0.6 & $<0.001$ \\
\hline
\end{tabular}

fibre as well as most micronutrients. Individuals in the traditional dietary pattern ate slightly more fat, significantly more SFA and significantly less PUFA, fibre, vitamin $\mathrm{C}$ as well as less vitamin $\mathrm{E}$, folate, $\mathrm{Zn}$, vitamin $\mathrm{A}, \beta$-carotene, uric acid, $n-3$ and $n-6$ fatty acids.

\section{Discussion}

In the present cross-sectional-study, the presence of any health problem was inquired but not derived by biochemical and clinical parameters. Consequently, due to the study design, it is not recommended to conduct statistical calculations to assess risks or odds for developing or preventing a disease. Instead, conclusions on nutritional and health status were drawn from the data on body composition and nutrient profile. Rizzo et $a l^{(46)}$ chose a similar approach in their study where nutrient profiles from different dietary patterns, such as nonvegetarian, vegetarian and vegan patterns, were evaluated concerning their known impact on the development of certain diseases.

After PCA and CA had been applied, three major dietary patterns were derived among adults in western Austria. Those clusters were labelled as 'health-conscious' dietary pattern and 'western' dietary pattern on the basis of 
previous studies, where similar dietary patterns in adult populations were found ${ }^{(47,48)}$, as well as 'traditional' dietary pattern based on traditional Austrian foods and meals ${ }^{(28,29)}$. In contrast to individuals following the western dietary pattern, those in the health-conscious dietary pattern group included a high number of women and were associated with the lowest prevalence of overweight/obesity, lowest BFP and a better nutrient profile, which could also be seen in previous studies ${ }^{(46,49,50)}$. Additionally, it has been shown before that the healthconscious dietary pattern, unlike the western dietary pattern, was characterized by mostly healthy food choices as well as a better nutrient profile and is associated with a lower prevalence of NCD, such as obesity, type 2 diabetes mellitus, hypertension and $\mathrm{CVD}^{(14-22)}$. Regardless of the dietary patterns, the study population could not meet the macronutrient profile (see Table 4) recommended by national and international guidelines ${ }^{(51,52)}$, with carbohydrate intake above $50 \mathrm{E} \%$, fat intake of $30 \mathrm{E} \%$ and protein intake between 10 and $15 \mathrm{E} \%$.

Notably, our study identified a high number of participants in the cluster of the traditional dietary pattern, whereas the amount of men and women within the cluster was similar. Although western influences with unhealthy but also healthy food choices are getting more integrated, traditional foods are still very present in everyday cooking in Austria. The traditional dietary pattern was characterized by high intakes of typical sweet dishes, dumplings, soups and stews. These meals are often prepared using butter, eggs and cream, which are reflected in the nutrient profile: even though the western dietary pattern was characterized by higher meat and fast food intakes, participants in the traditional dietary pattern had higher intakes of total fat and SFA and lower intakes of PUFA and dietary fibre.

\section{SFA and health risk}

Similar to the data of the Austrian Nutrition Study $2012^{(8)}$, fat intake was between 34 and $37 \mathrm{E} \%$. The proportion of SFA should not exceed $10 \mathrm{E} \%$ as recommended by national $^{(51)}$ and international guidelines ${ }^{(52)}$. In Austria, SFA intake was $15 \mathrm{E} \%$ in 2012, whereas in our study population SFA intake was $16 \mathrm{E} \%$. Mean SFA intake at $17 \mathrm{E} \%$ was highest in individuals who followed the traditional dietary pattern. Since $64 \%$ of the study population follows the traditional dietary pattern, these numbers appear to be of importance.

A high intake of SFA and low intake of PUFA have long been directly associated with $\mathrm{CVD}^{(53)}$. According to data by Statistics Austria ${ }^{(54)}$, all-cause mortality and mortality from CVD, type 2 diabetes mellitus and cancer were lowest in western Austria, including Tyrol. With the highest intake rate of SFA but the lowest rate of CVD mortality in Tyrol, the results seem to be congruent with recent discussions about the exact effects of fatty acids.
There is a consensus about achieving a significant reduction in CVD risk by replacing SFA by unsaturated fats, especially PUFA ${ }^{(52,55)}$. However, the Prospective Urban Rural Epidemiology (PURE) Study ${ }^{(56)}$ recently questioned these recommendations in the course of their latest findings wherein, compared with carbohydrates, total fat and SFA were associated with lower risk of total mortality and stroke. Additionally, total fat and types of fat were not associated with CVD, myocardial infarction or CVD mortality, whereas SFA had an inverse association with stroke. Although the study has been highly criticized due to methodological weaknesses ${ }^{(57)}$, also other studies $^{(58)}$ could not find a clear association between high intake of SFA and all-cause mortality, CHD, CHD mortality, ischaemic stroke or type 2 diabetes mellitus, but not neglecting the positive effect on total and LDL cholesterol. But in contrast to the isolated investigation of SFA as a nutrient, foods as a whole high in SFA have been associated with increased mortality ${ }^{(59,60)}$. According to a review by Silva Figueiredo et $a l^{(61)}$, an association with obesity and its associated disorders, such as insulin resistance, dyslipidaemia, metabolic inflammation and non-alcoholic fatty liver disease, exists. The consumption of SFA, MUFA and PUFA within in vivo, in vitro and human studies was evaluated, with PUFA possibly promoting benefits for obesity-related co-morbidities. The study also found that high-fat diets with a predominance of SFA influenced intestinal permeability damage, leading to the greater stimulus of endotoxin production and consequently greater inflammatory process which can be the preliminary stage of chronic disease.

The majority of observational studies use FFQ as the dietary assessment tool. Considering the latest contradictory findings referred to SFA, it can be assumed that there is a need for a consistent and more precise approach in data collection as well as data analysis. According to O'Sullivan et $a l .{ }^{(60)}$, studies using quantitative dietary assessments, such as multiple $24 \mathrm{~h}$ recalls, diet histories or diet records with sufficient length of follow-up and sufficient personal and lifestyle data to adequately adjust for potential confounders, are necessary to clarify the scientific evidence on the association between SFA and health. Also, a holistic approach of rather investigating foods and diets instead of isolated nutrients and their association with disease using consistent methods, as suggested by Mozzaffarian and Ludwig ${ }^{(13)}$, seems to be paramount for future studies.

\section{Dietary fibre and bealth protection}

While a high intake of SFA is known to have a negative impact on health, dietary fibre has taken on the role as a major health protector. However, fibre intake in the European population is mainly too low $^{(62)}$, also in Austria ${ }^{(8)}$, since daily intake of $30 \mathrm{~g}$ of dietary fibre is recommended $^{(51)}$. Mean daily intake in the Tyrolean population 
was $21 \mathrm{~g}$, whereas individuals following the healthconscious dietary pattern exceeded the recommendations with $31.5 \mathrm{~g}$. It can be assumed that the higher consumption of vegetables, fruits and whole grains is responsible for this. Mean fibre intake within the traditional dietary pattern, however, was $17.9 \mathrm{~g}$, not far behind the mean intake for individuals following the western dietary pattern at $18.2 \mathrm{~g}$. As a result, $87.7 \%$ of our study population did not reach the recommendations, which is reflected in the food intake: according to the Austrian dietary guidelines ${ }^{(63)}$, three portions of vegetables (375$600 \mathrm{~g}$ ) and two portions of fruits (250-300 g) should be consumed daily. In our study population, women reached only $36.9 \%$ of the recommended vegetable intake and $61.0 \%$ of the recommended fruit intake, while men also reached $37.3 \%$ of the recommended vegetable and $43.9 \%$ of the recommended fruit intake.

Considering the recent literature, this probably represents a risk factor for the development of $\mathrm{NCD}^{(64-66)}$. There are several meta-analyses and systematic reviews that describe a significant relative risk reduction for NCD by increasing the daily fibre intake ${ }^{(67-71)}$. Also, studies focusing on food intake rather than on single nutrients show a lower risk of developing NCD for people with high intakes of vegetables, fruits ${ }^{(72,73)}$ and whole grains ${ }^{(74)}$.

With the strong evidence for dietary fibre and foods that contain considerable amounts of dietary fibre being beneficial for health, there is a need to increase its daily intake in the population. Therefore, also in Austria, public health actions furthermore need to strongly address the higher intake of vegetables, fruits and whole grains.

\section{Strengths and limitations}

The present study was the first of its kind in Tyrol and is a milestone for future studies in this region. Despite several strengths, especially the data collection via two nonconsecutive $24 \mathrm{~h}$ recalls with the consideration of seasonal differences and the achievement of the requirements of standardized conditions as recommended by the European Food Safety Authority ${ }^{(38)}$, our study also has a few limitations. We could recruit participants only from the central area of Tyrol and therefore the results are representative only for the selected area. Variations in the dietary intakes among the population of Tyrol due to regional differences cannot be excluded. With lower response rates in men than in women, non-response bias is likely, and it was necessary to additionally recruit participants in regional companies to complete the missing sex and age groups. Therefore, they are not part of the original random sample. Furthermore, although known confounders were considered, residual confounding remains a possibility. Inadequate or incomplete adjustment for lifestyle and dietary factors could also potentially influence the results of our study.
Lastly, as Engeset et al. ${ }^{(44)}$ address in their study, there have been critics regarding the use of the combination of both multivariate statistical procedures of PCA and CA to empirically derive dietary patterns. This method may be affected by subjective analytic decisions and results depend on the individual sample and decisions about variable input format. Thus, reproducibility of the derivation of dietary patterns can be limited, although similar patterns labelled as western, healthy and traditional dietary patterns have been found in numerous studies. Also, they mention that clusters do not and cannot explain all the food choices of the population but can be interpreted in terms of basic food group selection. Equally, we were looking for similarities of eating behaviour and for some common patterns in the Tyrolean population, nevertheless acknowledging that every individual has his or her unique food choices that cannot be reflected within the dietary patterns overall.

\section{Conclusion}

The prevalence of overweight and obesity was higher in individuals following the traditional and western dietary patterns than in those following the health-conscious dietary pattern. The intakes of SFA and PUFA as well as dietary fibre were higher and lower, respectively, in the traditional dietary pattern compared with both other dietary patterns. According to the latest findings, this possibly represents a health risk factor and needs to be taken into consideration for health care and nutritional interventions. Therefore, individuals in Tyrol who mostly eat in a traditional way should be encouraged to increase their consumption of vegetables, fruits, whole grains and healthy fats. Also, adequate alternatives in food preparation provide good opportunities to eat healthier while maintaining tradition. Finally, it is important to regularly evaluate regional dietary habits via monitoring, not only for planning individual nutritional therapy, but also for welldirected public health actions.

\section{Acknowledgements}

Acknowledgements: The authors thank colleagues from the Department of Nutritional Sciences at the University of Vienna who supported the study in organizational issues and provided insight and expertise that greatly assisted the research. Financial support: This research project was partially funded by the Tiroler Wissenschaftsfonds (grant reference UNI-0404/1378) and the Health University of Applied Sciences Tyrol. The funders had no role in the design, analysis or writing of this article. Conflict of interest: The authors declare that they have no conflict of interest. Authorship: S.E. and J.E. contributed equally to this work. S.E. analysed and interpreted the data and 
wrote the article. J.E. had a major role in organizing the study and collecting the data. B.P. was head of project management and formulated the research questions. V.H., P.R. and J.K. supported the study in organizational issues and with valuable expertise. R.R. was contact partner for statistical questions and A.E.P. supervised the study and revised the article. Ethics of human subject participation: This study was conducted according to the guidelines laid down in the Declaration of Helsinki and all procedures involving human subjects were reviewed and approved by the ethics committee at the UMIT (Private University for Health Sciences, Medical Informatics and Technology Tyrol) (reference number 728/13). Written informed consent was obtained from all subjects.

\section{Supplementary material}

To view supplementary material for this article, please visit https://doi.org/10.1017/S1368980018003270

\section{References}

1. US Department of Health and Human Services \& US Department of Agriculture (2015) Dietary Guidelines for Americans 2015-2020, 8th ed. Washington, DC: US Government Printing Office.

2. World Health Organization (2006) Global Strategy on Diet, Physical Activity and Health: A Framework to Monitor and Evaluate Implementation. Geneva: WHO.

3. German Nutrition Society (2017) 10 guidelines of the German Nutrition Society (DGE) for a wholesome diet. https:// www.dge.de/fileadmin/public/doc/en/10-guidelines-whole some-diet-dge.pdf (accessed July 2018).

4. World Health Organization (2016) Obesity and overweight: Fact sheet. http://www.wpro.who.int/mediacentre/fact sheets/obesity/en/ (accessed August 2017).

5. Griebler R, Geißler W \& Winkler P (2013) Zivilisationskrankheit Diabetes: Ausprägungen-Lösungsansätze-Herausforderungen. Österreichischer Diabetesbericht 2013. Wien: Bundesministerium für Gesundheit.

6. Kiefer I, Rieder A, Rathmanner T et al. (2006) Erster österreichischer Adipositasbericht: Grundlage für die zukünftigen Handlungsfelder: Kinder, Jugendliche, Erwachsene. Vienna: Altern mit Zukunft.

7. Gergely SM (1982) Österreichischer Ernährungsbericht 1982. Wien: Bundesministerium für Gesundheit und Umweltschutz.

8. Elmadfa I, Hasenegger V, Wagner K et al. (2012) Österreichischer Ernährungsbericht 2012. Wien: Bundesministerium für Gesundheit.

9. Hu FB (2002) Dietary pattern analysis: a new direction in nutritional epidemiology. Curr Opin Lipidol 13, 3-9.

10. Fardet A \& Rock E (2014) Toward a new philosophy of preventive nutrition: from a reductionist to a holistic paradigm to improve nutritional recommendations. Adv Nutr $\mathbf{5}$, 430-446.

11. Newby PK \& Tucker KL (2004) Empirically derived eating patterns using factor or cluster analysis: a review. Nutr Rev 62, 177-203.

12. Mozaffarian D (2016) Dietary and policy priorities for cardiovascular disease, diabetes and obesity: a comprehensive review. Circulation 133, 187-225.
13. Mozaffarian D \& Ludwig DS (2010) Dietary guidelines in the 21st century - a time for food. JAMA 304, 681-682.

14. Smethers AD \& Rolls BJ (2018) Dietary management of obesity: cornerstones of healthy eating patterns. Med Clin North Am 102, 107-124.

15. Shu L, Zheng P-F, Zhang X-Y et al. (2015) Association between dietary patterns and the indicators of obesity among Chinese: a cross-sectional study. Nutrients 7, 7995-8009.

16. Rezagholizadeh F, Djafarian K, Khosravi S et al. (2017) $A$ posteriori healthy dietary patterns may decrease the risk of central obesity: findings from a systematic review and metaanalysis. Nutr Res 41, 1-13.

17. Maghsoudi Z, Ghiasvand R \& Salehi-Abargouei A (2016) Empirically derived dietary patterns and incident type 2 diabetes mellitus: a systematic review and meta-analysis on prospective observational studies. Public Health Nutr 19, 230-241.

18. Alhazmi A, Stojanovski E, McEvoy M et al. (2014) The association between dietary patterns and type 2 diabetes: a systematic review and meta-analysis of cohort studies. $J$ Hum Nutr Diet 27, 251-260.

19. InterAct Consortium (2014) Adherence to predefined dietary patterns and incident type 2 diabetes in European populations: EPIC-InterAct Study. Diabetologia 57, 321-333.

20. Ndanuko RN, Tapsell LC, Charlton KE et al. (2016) Dietary patterns and blood pressure in adults: a systematic review and meta-analysis of randomized controlled trials. Adv Nutr 7, 76-89.

21. Mazidi M, Pennathur S \& Afshinnia F (2017) Link of dietary patterns with metabolic syndrome: analysis of the National Health and Nutrition Examination Survey. Nutr Diabetes 7, e255.

22. Rodríguez-Monforte $M$, Flores-Mateo $G$ \& Sánchez $E$ (2015) Dietary patterns and CVD: a systematic review and meta-analysis of observational studies. Br J Nutr 114, 1341-1359.

23. Lee Y, Kwon O, Shin CS et al. (2015) Use of bioelectrical impedance analysis for the assessment of nutritional status in critically ill patients. Clin Nutr Res 4, 32-40.

24. Chuang H-H, Li W-C, Sheu B-F et al. (2012) Correlation between body composition and risk factors for cardiovascular disease and metabolic syndrome. Biofactors 38, 284-291.

25. Nunan D, Mahtani KR, Roberts N et al. (2013) Physical activity for the prevention and treatment of major chronic disease: an overview of systematic reviews. Syst Rev 2, 56.

26. Britton KA, Massaro JM, Murabito JM et al. (2013) Body fat distribution, incident cardiovascular disease, cancer, and allcause mortality. J Am Coll Cardiol 62, 921-925.

27. Andreoli A, Garaci F, Cafarelli FP et al. (2016) Body composition in clinical practice. Eur J Radiol 85, 1461-1468.

28. Trichopoulou A, Soukara S \& Vasilopoulou E (2007) Traditional foods: a science and society perspective. Trends Food Sci Technol 18, 420-427.

29. Weichselbaum E, Benelam B \& Soares Costa H (2009) Traditional Foods in Europe. Synthesis Report no 6. Norwich: European Food Information Resource.

30. European Commission (2008) Database Of Origin and Registration (DOOR). http://ec.europa.eu/agriculture/quality/door/list.html?\&recordStart=0\&filter.dossierNumber=\& filter.comboName $=\&$ filterMin. $m i l e s t o n e \_$mask $=\&$ filterMin milestone $=\&$ filterMax.milestone__mask $=\&$ filterMax.mile stone $=\&$ filter. country $=$ AT\&filter.category $=\&$ filter.type $=\&$ filter.status $=\&$ locale $=$ en (accessed June 2018).

31. European Commission (2003) Regulation (EC) No 1059/ 2003 of the European Parliament and of the Council of 26 May 2003 on the establishment of a common classification of territorial units for statistics (NUTS). Official Journal of the European Union L154, 21.06.2003, 1-41. 
32. European Commission (2011) Regions in the European Union: Nomenclature of Territorial Units for Statistics NUTS 2010/EU-27. Luxembourg: Publications Office of the European Union.

33. Statistics Austria (2014) NUTS-332 Innsbruck population in age categories. https://www.statistik.at/web_en/statistics/ index.html (accessed June 2018).

34. European Commission (2012) ECHI Indicator Development and Documentation: Joint Action for ECHIM Final Report part II. Bilthoven: National Institute for Public Health and the Environment (RIVM).

35. Black AE (2000) Critical evaluation of energy intake using the Goldberg cut-off for energy intake:basal metabolic rate. A practical guide to its calculation, use and limitations. Int J Obes Relat Metab Disord 24, 1119-1130.

36. Goldberg GR, Black AE, Jebb SA et al. (1991) Critical evaluation of energy intake data using fundamental principles of energy physiology: 1 . Derivation of cut-off limits to identify under-recording. Eur J Clin Nutr 45, 569-581.

37. Slimani N, Casagrande C, Nicolas G et al. (2011) The standardized computerized 24-h dietary recall method EPIC-Soft adapted for pan-European dietary monitoring. Eur J Clin Nutr 65, Suppl. 1, S5-S15.

38. European Food Safety Authority (2009) General principles for the collection of national food consumption data in the view of a pan-European dietary survey. EFSA J 7, 1435.

39. Max Rubner-Institut, Bundesforschungsinstitut für Ernährung und Lebensmittel (2008) Nationale Verzehrsstudie II. Ernährung Wissenschaft Praxis 2, 77-81.

40. Max Rubner-Institut, Bundesforschungsinstitut für Ernährung und Lebensmittel (2017) Bundeslebensmittelschlüssel (BLS)-Version 3.02. http://www.blsdb.de (accessed June 2018).

41. Schendera CFG (2010) Clusteranalyse mit SPSS: Mit Faktorenanalyse. München: Oldenbourg.

42. Shang X, Li Y, Liu A et al. (2012) Dietary pattern and its association with the prevalence of obesity and related cardiometabolic risk factors among Chinese children. PLoS One 7, e43183.

43. Choi H-J, Joung H, Lee H-J et al. (2011) The influence of dietary patterns on the nutritional profile in a Korean child cohort study. Osong Public Health Res Perspect 2, 59-64.

44. Engeset D, Alsaker E, Ciampi A et al. (2005) Dietary patterns and lifestyle factors in the Norwegian EPIC cohort: the Norwegian women and cancer (NOWAC) study. Eur J Clin Nutr 59, 675-684.

45. World Health Organization (2000) Obesity: Preventing and Managing the Global Epidemic. Report of a WHO Consultation. WHO Technical Report Series no. 894. Geneva: WHO.

46. Rizzo NS, Jaceldo-Siegl K, Sabate J et al. (2013) Nutrient profiles of vegetarian and non-vegetarian dietary patterns. $J$ Acad Nutr Diet 113, 1610-1619.

47. Hsiao PY, Mitchell DC, Coffman DL et al. (2013) Dietary patterns and relationship to obesity-related health outcomes and mortality in adults 75 years of age or greater. $J$ Nutr Health Aging 17, 566-572.

48. Wang C-J, Shen Y-X \& Liu Y (2016) Empirically derived dietary patterns and hypertension likelihood: a metaanalysis. Kidney Blood Press Res 41, 570-581.

49. Emmett PM, Jones LR \& Northstone K (2015) Dietary patterns in the Avon Longitudinal Study of parents and children. Nutr Rev 73, Suppl. 3, 207-230.

50. Schrijvers JK, McNaughton SA, Beck KL et al. (2016) Exploring the dietary patterns of young New Zealand women and associations with BMI and body fat. Nutrients 8,8 .

51. Deutsche Gesellschaft für Ernährung, Österreichische Gesellschaft für Ernährung, Schweizerische Gesellschaft für
Ernährungsforschung et al. (2017) Referenzwerte für die Nährstoffzufubr, 2nd ed. Bonn: DGE, ÖGE and SSG/SSN.

52. Food and Agriculture Organization of the United Nations (2010) Fats and Fatty Acids in Human Nutrition: Report of an Expert Consultation 10-14 November 2008, Geneva. Geneva: FAO.

53. Siri-Tarino PW, Chiu S, Bergeron N et al. (2015) Saturated fats versus polyunsaturated fats versus carbohydrates for cardiovascular disease prevention and treatment. Annu Rev Nutr 35, 517-543.

54. Statistics Austria (2018) Jahrbuch der Gesundheitsstatistik 2016. https://www.statistik.at/wcm/mvc/publicationsCata logue $/$ redirectDetailedView?pubId $=495 \&$ sectionId $=82$ (accessed July 2018).

55. Wang DD \& Hu FB (2017) Dietary fat and risk of cardiovascular disease: recent controversies and advances. Annu Rev Nutr 37, 423-446.

56. Dehghan M, Mente A, Zhang X et al. (2017) Associations of fats and carbohydrate intake with cardiovascular disease and mortality in 18 countries from five continents (PURE): a prospective cohort study. Lancet 390, 2050-2062.

57. Richter M, Egert S, Watzl B et al. (2018) Das PURE Desaster: Vorschnelle Schlagzeilen führen zu unnötiger Verunsicherung von Verbrauchern und Patienten. Aktuel Ernahrungsmed 43, 173-177.

58. Souza RJ de, Mente A, Maroleanu Aet al. (2015) Intake of saturated and trans unsaturated fatty acids and risk of allcause mortality, cardiovascular disease, and type 2 diabetes: systematic review and meta-analysis of observational studies. BMJ 351, h3978.

59. Larsson SC \& Orsini N (2014) Red meat and processed meat consumption and all-cause mortality: a meta-analysis. $A m \mathrm{~J}$ Epidemiol 179, 282-289.

60. O'Sullivan TA, Hafekost K, Mitrou F et al. (2013) Food sources of saturated fat and the association with mortality: a meta-analysis. Am J Public Health 103, e31-e42.

61. Silva Figueiredo P, Carla Inada A, Marcelino G et al. (2017) Fatty acids consumption: the role of metabolic aspects involved in obesity and its associated disorders. Nutrients 9, 10 .

62. Stephen AM, Champ MM-J, Cloran SJ et al. (2017) Dietary fibre in Europe: current state of knowledge on definitions, sources, recommendations, intakes and relationships to health. Nutr Res Rev 30, 149-190.

63. Bundesministerium für Arbeit, Soziales, Gesundheit und Konsumentenschutz (2010) Die Österreichische Ernährungspyramide. https://www.bmgf.gv.at/home/Ernaeh rungspyramide (accessed June 2018).

64. Murphy N, Norat T, Ferrari P et al. (2012) Dietary fibre intake and risks of cancers of the colon and rectum in the European prospective investigation into cancer and nutrition (EPIC). PLoS One 7, e39361.

65. InterAct Consortium (2015) Dietary fibre and incidence of type 2 diabetes in eight European countries: the EPICInterAct Study and a meta-analysis of prospective studies. Diabetologia 58, 1394-1408.

66. Ye EQ, Chacko SA, Chou EL et al. (2012) Greater whole-grain intake is associated with lower risk of type 2 diabetes, cardiovascular disease, and weight gain. J Nutr 142, 1304-1313.

67. Wu Y, Qian Y, Pan Y et al. (2015) Association between dietary fiber intake and risk of coronary heart disease: a meta-analysis. Clin Nutr 34, 603-611.

68. Threapleton DE, Greenwood DC, Evans CEL et al. (2013) Dietary fibre intake and risk of cardiovascular disease: systematic review and meta-analysis. BMJ 347, f6879.

69. Ericson U, Brunkwall L, Alves Dias J et al. (2018) Food patterns in relation to weight change and incidence of type 2 diabetes, coronary events and stroke in the Malmö Diet and Cancer Cohort. Eur J Nutr. Published online: 31 May 2018. doi: 10.1007/s00394-018-1727-9. 
70. World Cancer Research Fund \& American Institute for Cancer Research (2018) Diet, nutrition, physical activity and cancer: a global perspective. Continuous update project expert report 2018. https://www.wcrf.org/dietandcancer (accessed June 2018).

71. Scientific Advisory Committee on Nutrition (2015) Carbobydrates and Health. London: The Stationery Office.

72. Aune D, Giovannucci E, Boffetta P et al. (2017) Fruit and vegetable intake and the risk of cardiovascular disease, total cancer and all-cause mortality-a systematic review and dose-response meta-analysis of prospective studies. Int $J$ Epidemiol 46, 1029-1056.

73. Alissa EM \& Ferns GA (2017) Dietary fruits and vegetables and cardiovascular diseases risk. Crit Rev Food Sci Nutr 57, 1950-1962.

74. Aune D, Keum N, Giovannucci E et al. (2016) Whole grain consumption and risk of cardiovascular disease, cancer, and all cause and cause specific mortality: systematic review and dose-response meta-analysis of prospective studies. BMJ $\mathbf{3 5 3}$, i2 2716 . 